\title{
Antonia S. Byatt, Ritratti in letteratura
}

\section{Marco Stupazzoni}

\section{Q OpenEdition}

\section{Journals}

\section{Edizione digitale}

URL: http://journals.openedition.org/studifrancesi/30461

DOI: 10.4000/studifrancesi.30461

ISSN: 2421-5856

\section{Editore}

Rosenberg \& Sellier

\section{Edizione cartacea}

Data di pubblicazione: 1 avril 2006

Paginazione: 173

ISSN: 0039-2944

\section{Notizia bibliografica digitale}

Marco Stupazzoni, «Antonia S. Byatt, Ritratti in letteratura», Studi Francesi [Online], 148 (XLX | I) | 2006,

online dal 30 novembre 2015, consultato il 18 avril 2021. URL: http://journals.openedition.org/ studifrancesi/30461; DOI: https://doi.org/10.4000/studifrancesi.30461

\section{Questo documento è stato generato automaticamente il 18 avril 2021.}

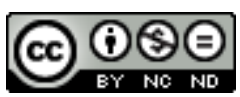

Studi Francesi è distribuita con Licenza Creative Commons Attribuzione - Non commerciale - Non opere derivate 4.0 Internazionale. 


\title{
Antonia S. Byatt, Ritratti in letteratura
}

\author{
Marco Stupazzoni
}

\section{NOTIZIA}

ANTONIA S. BYATT, Ritratti in letteratura, traduzione di ANNA NADOTTI e FAUSTO GALUZZI,

Milano, Archinto, 2004, pp. 99.

1 Le relazioni, spesso ambigue ma sempre feconde e suggestive, tra arte e letteratura sono evocate in questo acuto e piacevole saggio di A. S. Byatt: è, in particolare, il tema del ritratto nelle sue molteplici espressioni e variazioni letterarie ad attirare in modo specifico l'attenzione della scrittrice inglese in considerazione del fatto che il potere evocativo oltre che documentario dei ritratti e il rapporto seduttivo che si instaura tra l'artista e il modello dipinto sono al centro di molti capolavori della letteratura occidentale otto-novecentesca.Tra le opere di autori francesi su cui l'A. concentra maggiormente la sua attenzione, figurano Le Chef-d'oeuvre inconnu di Balzac, L'Oeuvre di Zola e Du côté de chez Swann di Proust.

2 In un romanzo o in un racconto, «si possono ritrarre cose invisibili »: se i ritratti pittorici sono variamente oggetto della letteratura, nei ritratti letterari, osserva A.S. Byatt, "gli scrittori fanno affidamento sulle infinite immagini visive dei singoli lettori e sul loro costruttivo lavoro di visualizzazione» (p. 6). Da questo punto di vista, Le Chef-d'oeuvre inconnu di Balzac, in quanto "favola sulla raffigurazione» (p. 28) e «mito di creazione e distruzione» (p. 27), rappresenta agli occhi della scrittrice inglese probabilmente «l'opera più celebre che sia stata mai scritta su un ritratto » (p. 21). Una questione importante che, secondo l'autrice, merita di essere posta in evidenza nell'analisi del racconto balzachiano è quella di stabilire se il quadro di Frenhofer sia effettivamente « un ritratto fallimentare, o se invece sono i giovani pittori [Porbus e Poussin] che non sanno come guardarlo » (p. 23). Scrive, a questo proposito, A. S. Byatt: " personalmente, credo che un'attenta lettura suggerisca che il ritratto era un disastro, 
un passo troppo in là nell'arduo e sensualmente ossessivo processo di costruzione della donna in pittura. Ma subito aggiungo che Balzac capiva, e sapeva tradurre in parole il rapporto tra colpi di pennello, luce e corpi, i problemi tecnici, la differenza tra ciò che è automatico e ciò che è immaginato » (pp. 23-24).

3 La parte dello studio dell'A. sul Chef-d'oeuvre inconnu è stata pubblicata dal quotidiano «La Repubblica» il 25 ottobre 2004 con il titolo : Balzac. Storia di un racconto meraviglioso. 